\title{
Can metal replacement increase the antitumor activity of azurin? (in vitro study)
}

\author{
Maha A Ali ${ }^{*}$, Mervat S Mohamed ${ }^{2}$ and Ramy G Sedek ${ }^{2}$ \\ 1Department of Biophysics, Faculty of Science, Cairo University, Giza, Egypt \\ ${ }^{2}$ Department of Biochemistry, Faculty of Science, Cairo University, Giza, Egypt
}

\begin{abstract}
Azurin is a member of blue-copper proteins family which induces apoptosis in cancer cells. In the present work, azurin (Az) has been modified via replacement of copper at active site with cobalt and nickel. FTIR revealed that its secondary structure is practically indistinguishable from that of its derivatives. UV spectroscopy and DSC results revealed that native form of $\mathrm{Az}$ is more stable than $\mathrm{Co}$ - and $\mathrm{Ni}$ forms. SRB was used to elucidate their possible anti-tumor effect on cancer cell lines from breast and colon cells (MCF-7 and HCT116, respectively). To our best knowledge, this is the first time metal replacement of Az has been used with cell line. It appears that this process is the predominant reason for the effectiveness of $\mathrm{Az}$. Experimental results showed that the anti-tumor activity of $\mathrm{Cu}-$ and $\mathrm{Co} \mathrm{Az}$ (at concentration $\leq 25 \mu \mathrm{g} / \mathrm{L}$ ) is higher for colon-relative to breast cells, while that for Ni-Az is higher for both cells (at low concentration, $5 \mu \mathrm{g} / \mathrm{L}$ ). Hence, according to our findings it was revealed that $\mathrm{Ni}$-Az form has the most extensive anti-antitumor effect on breast-and colon cancer cells. This highlights that Ni may be bona fide copper ion impersonator in vivo.
\end{abstract}

\section{Introduction}

Currently cancer represents one of the greatest burdens of our society and will remain a serious and challenging major public health problem in the future years. Each year about 12.7 million people are diagnosed with cancer, and approximately 7.6 million die from it, clearly demonstrating the magnitude of this disease in human population. Breast cancer is the second most common cancer worldwide, with 1.4 million cases being diagnosed annually, and the first cause of cancerrelated death among women (458,000 deaths/year) [1]. Current cancer treatments rely on surgery, chemo-and radiotherapy, or even hormone therapy, in the case of breast cancer. However, these therapies can reveal serious and systemic side-effects in patient's health due to its high toxicity and lack of cancerous tissue specificity [2]. Additionally not every patient responds efficiently to chemotherapy or other treatments, since cancer cells can undergo micro-evolution and rapidly render cancer cells resistant to drug therapy [3]. Therefore, today we face new challenges regarding cancer treatment and cancer patients, especially those which do not respond to conventional therapies, demand for new, more efficient and selective drugs or therapies to fight this disease.

Newer and alternative anti-cancer therapies are under development and are inevitable to reach more successful results against cancer than the conventional radio-and chemotherapies. The use of microorganisms and its derived products, especially proteins, to treat this disease are being broadly explored and would probably overcome the flaws unspecific cancer treatments.

For the first time in 1956, the Pseudomonas aeruginosa bacterium was reported to contain a blue protein [4]. They proposed the name 'azurin' (Az) for this class of proteins due to purplish shade of blue of the copper ions present in their structure. It functions as an electron carrier [5] and eradicates the host defense system by encouraging apoptosis in phagocyte cells [6]. However, a new and interesting role regarding $\mathrm{Az}$ was revealed in 2000, when Zaborina, et al. [7] reported Az cytotoxic and apoptosis-inducing activities towards murine macrophage cell line J774. Later it was shown that Az can also trigger apoptosis and lead to significant cytotoxicity in different human tumor cell lines as breast cancer (MCF-7), melanoma (UISO-Mel-2) and osteosarcoma (U2OS) cells $[8,9]$. Interestingly $\mathrm{Az}$ exhibits preferentially selectivity against tumor cell lines, showing much less cytotoxic and apoptotic effects towards normal cell lines [10].

Since $\mathrm{Az}$ has been reported to be a potential anticancer protein against breast cancer cell lines, researchers are searching for novel methods to enhance its production. Ramachandran, et al. [11] focused on enhanced $\mathrm{Az}$ synthesis from four different strains of $P$. aeruginosa with apparent homogeneity and stability by adding both $\mathrm{CuSo}_{4}$ and $\mathrm{KNO}_{3}$ in the culture medium.

Substitution of the naturally occurring metals in metallo-proteins can be considered as a kind of site directed mutation. Metal substitutions in proteins have previously been successfully used to probe structural and electronic states of metal sites in these proteins. Metal ions, such as $\mathrm{Ni}$ (II) and Co (II), have then been used as a replacement of the native metal ion in many blue copper proteins.

In the present work, $\mathrm{Az}$ has been modified is via replacement of copper at the active site with other metal ions. We have chosen to investigate the interaction of cobalt and nickel metals with P. aeruginosa Az. There are several reasons for studying the binding of $\mathrm{Ni}$ (II) and $\mathrm{Co}$ (II) to Az. The atomic number of $\mathrm{Co}, \mathrm{Ni}$ and $\mathrm{Cu}$ is 27, 28 and 29

Correspondence to: Maha Anwar Ali, Department of Biophysics, Faculty of Science, Cairo University, Giza, P. O. Box 12613, Egypt, E-mail: amaha@sci.edu. eg and maha_areeg@yhoo.com

Key words: azurin, antitumor activity, metal replacement

Received: August 31, 2017; Accepted: September 13, 2017; Published: September 18, 2017 
respectively. They belong to the first transition series. The energies of the $3 \mathrm{~d}$ and $4 \mathrm{~s}$ orbitals in the neutral atoms are quite similar, and their configurations are $3 \mathrm{dn} 4 \mathrm{~s} 2$ except for $\mathrm{Cu}(3 \mathrm{~d} 104 \mathrm{~s} 1)$, which is attributed to the stability of the filled $\mathrm{d}$ shell. In addition, cobalt containing compounds recently attracted considerable interest as systemic anticancer agents [12], while nickel (II) is vital for living beings [13] and it has been reported that $\mathrm{Ni}$ has apoptogenic capabilities [14].

On such a background we use UV absorption spectroscopy (UV) and denaturation experiments, monitored by differential scanning calorimetry (DSC), to investigate the effect of metal substitution on Az stability. Then cell line (SRB) was used to describe and elucidate their possible anti-tumour and cytotoxic effects on cancer cell lines from breast and colon (MCF-7 and HCT116, respectively). To our best knowledge, this is the first time metal replacement of $\mathrm{Az}$ has been used with cell line.

\section{Experimental}

\section{Materials and samples preparation}

All the chemicals used in this work were of analytical reagent grade and obtained from Sigma Chemical Co.

Holo Az (with cofactor) from Pseudomonas Aeruginosa was obtained as previously described [15]. Apo-Az (without cofactor ) was prepared by a cyanide treatment of the holo form according to the procedure described elsewhere by dialysis against $0.1 \mathrm{M} \mathrm{KCN}$ in $20 \mathrm{mM}$ tris- $\mathrm{HCl}, \mathrm{pH}=8$, for 14 days at room temperature [16]. After cyanide treatment, the protein was dissolved in $10 \mathrm{mM}$ tris-base buffer at $\mathrm{pH}=8$. The ionic strength was adjusted at $0.1 \mathrm{M}$ by sodium chloride. Incubation of apo-Az with a three-fold excess of $\mathrm{Cu}$ (II) resulted in a rapid reconstitution of the holo-form. The concentration of apo$\mathrm{Az}$ was determined by measuring the UV absorbance of the protein solution at $280 \mathrm{~nm}$.

The Az metallo-derivatives were prepared by adding a 5-10 folds excess of metal ions (cobalt (II) sulfate and nickel (II) sulfate) to the apo-protein solution. The metal uptake was allowed to take place overnight at $4{ }^{\circ} \mathrm{C}$. Reconstitution with $\mathrm{Ni}$ (II) gave a pale green solution, while that with Co (II) resulted in a yellow solution.

\section{Ultraviolet absorption spectroscopy (UV)}

UV optical spectra were recorded at room temperature $\left(25^{\circ} \mathrm{C}\right)$ in alcm cell in a Unicam UV 2-300 UV/visible spectrometer, in the wavelength region $200-800 \mathrm{~nm}$. The reported UV spectra were the average of 3 scans. The error in the reading was less than $8 \%$ (standard curve estimation). The blank employed for baseline subtraction consisted of tris-base buffer.

\section{Fourier transform infrared spectroscopy (FTIR)}

FTIR spectra were recorded using a double beam IR spectrometer of type Jasco-460 (FTIR plus, Japan). Each spectrum is recorded over wave number range $4000-400 \mathrm{~cm}^{-1}$. Az samples were mixed intimately with finely powdered $\mathrm{KBr}$ and the mixture is squeezed in a press to about 1000 atmospheres. Under these conditions the $\mathrm{KBr}$ becomes glassy and forms a thin translucent disc in which the finally ground sample is suspended and we kept the tris-base buffer as a background medium and performed all measurements at room temperature.

\section{Differential scanning calorimetry (DSC)}

DSC analysis was performed by a Shimadzu DSC-50 calorimeter. Samples were scanned from room temperature to $100^{\circ} \mathrm{C}$, with a heating rate $1^{\circ} \mathrm{C} / \mathrm{min}$. The protein $(10 \mu \mathrm{g} / \mathrm{ml})$ was dissolved in $\mathrm{mM}$ tris-base buffer at $\mathrm{pH}=8$. The ionic strength was adjusted at 0.1 by sodium chloride. The thermogram represents the enthalpy flow rate in $\mathrm{mW}$ on the $\mathrm{Y}$-axis and temperature on the $\mathrm{X}$-axis.

\section{Measurement of potential cytotoxicity by SRB assay}

Cell lines used for testing in vitro cytotoxicity included MCF-7 and HCT116 derived from human breast and colon carcinoma cell lines respectively were supplied from National Cancer Institute, Egypt. All of the procedures concerning the cell culture maintenance and treatment were carried out in a "Napaco" Laminar flow cabinet.

The potential cytotoxicity of Az was tested [17]. Cells were plated on 96-multiwell plate (104cells/well) for 24 hours before treatment with $\mathrm{Az}$ to allow attachment of cell to the wall of the plate. Different concentrations of $\mathrm{Az}$ under test $(0,5,12,25$ and $50 \mu \mathrm{g} / \mathrm{mL})$ were added to the cell monolayer triplicate wells which prepared for each individual dose. Monolayer cells were incubated with $\mathrm{Az}$ for 48 hours at $37^{\circ} \mathrm{C}$ and in atmosphere of 5\% CO2. After 48 hours, cells were fixed, washed and stained with SRB stain. Excess stain was washed with acetic acid and attached stain was recovered with Tris EDTA buffer. The relation between surviving fraction and $\mathrm{Az}$ concentration is plotted to get the survival curve of each tumor cell line after the specified Az.

\section{Statistics}

The data processing included the variance ANOVA test with $\mathrm{P}<0.05$ taken as significance level, using Microsoft EXCEL for PC.

\section{Results and discussion}

\section{Spectroscopic characterization of $\mathrm{Cu}$ (II)-, Ni (II)-and Co (II) azurin}

The purity of $\mathrm{Az}$ was checked by PAGE and UV-visible spectroscopy. Purified $\mathrm{Cu}$ (II)- $\mathrm{Az}$ had an $\mathrm{A}_{625} / \mathrm{A}_{280}$ ratio of 0.54-0.55. After the cyanide treatment, on introducing $\mathrm{Cu}$ (II) into the apo- $\mathrm{Az}$, the characteristic blue color of native $\mathrm{Az}$ rapidly developed, and the absorbance ratio $\left(\mathrm{A}_{625} / \mathrm{A}_{280}\right)$ of the reconstituted protein $\mathrm{Cu}$ (II) Az was 0.5 or greater. It has been shown that under comparable conditions, $\mathrm{Cu}$ (I1) was taken up by apo-Az much more rapidly than $\mathrm{Ni}$ (II) or Co (I1) [18]. On introducing $\mathrm{Ni}$ (I1) into a solution of apo-Az, a yellow color developed, but much less rapidly than the coloration induced by $\mathrm{Cu}$ (II), while a faint bluish color appeared when Co (I1) was used.

We have verified that $\mathrm{Ni}$ and $\mathrm{Co}$ can metallate apo-Az using absorption spectroscopy which demonstrates that these metals effectively metallates $P$. aeruginosa apo-azurin in solution as presented in Figure 1. Az has strong charge-transfer absorption with maximum absorbance at around $625 \mathrm{~nm}$ due to the bond between $\mathrm{Cu}$ and Cys112 [19]. The absorption band probes the oxidation state of the copper ion and other alterations around it [20]. As shown in Figure 1, Niand Co-Az have intense peak near 391 and $308 \mathrm{~nm}$ respectively, this is in agreement with Czernuszewicz, et al. [21]. The charge-transfer absorption bands of the nickel (II) and copper (II) derivatives appear in the visible region, while that of cobalt (II) derivative appear in the near-UV region [22]. These shifts in peaks positions is due to ligandto-metal charge transfer transitions, which are expected to increase in energy as one moves from right to left across the periodic table as a result of the acceptor d-orbitals shifting to higher energy.

\section{FTIR analysis}

The functional groups of Az were studied using FTIR spectrum. Az provides a convenient model to study infrared spectra of proteins forming characteristic $\beta$-barrel structures. Figure 2 shows the FTIR 


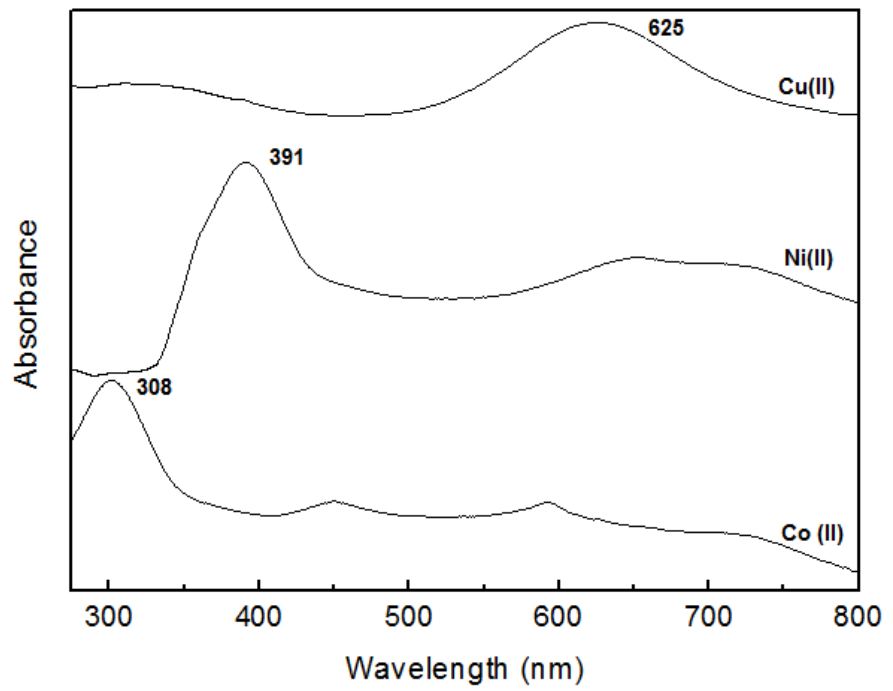

Figure 1. Room-temperature absorption spectra of (a) native P. aeruginosa azurin and its (b) $\mathrm{Ni}$ (II)-and (c) Co (II) substituted derivatives

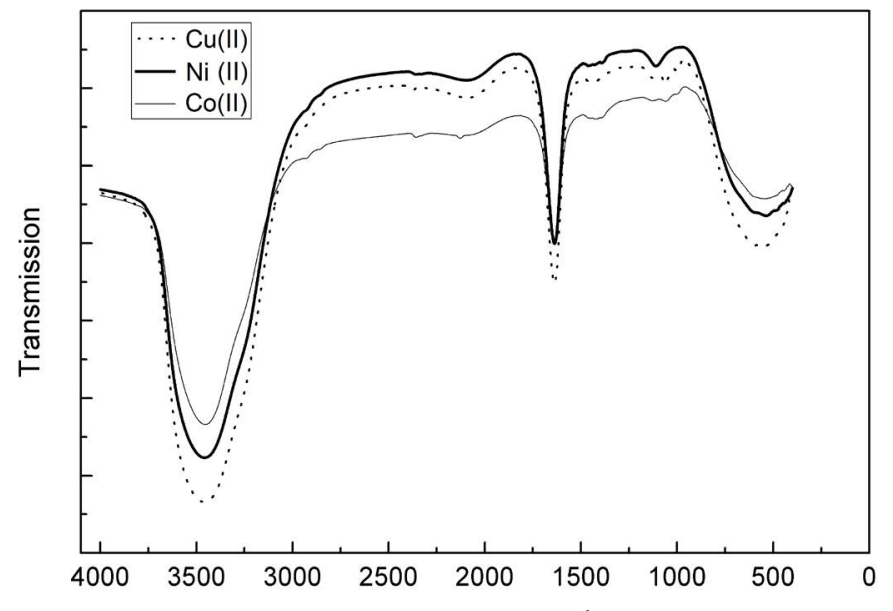

Figure 2. FTIR spectra of native P. aeruginosa azurin (dot line) and it's Co (II)-(thick line) and $\mathrm{Ni}$ (II)-(thin line) substituted derivatives recorded at room temperature

spectrum of wild-type (Cu-containing) P. aeruginosa $\mathrm{Az}$ and its $\mathrm{Co}$ (II)-and Ni (II) substituted metallo-derivatives recorded at room temperature.

Metal ion variation allowed a possibility to assess the extent to which protein structural constraints govern conformational balance in blue copper centers. Moreover, it has been suggested that replacement of native $\mathrm{Cu}$ (II) by other metal ions should have minimal effects on the metal binding site because of the existence of an extensive network of hydrogen bonds and other interactions that make the copper site more rigid and thereby a more ordered part of the structure [23]. As shown in Figure 2, the secondary structure of native $\mathrm{Az}$ is practically indistinguishable from that of cobalt and nickel derivatives. This similarity does not, of course, preclude localized differences in the vicinity of the active site. Crystal structures of apo-and holo Az have shown that the overall three-dimensional structure is identical with and without a metal (copper or zinc) cofactor [24].

As presented in Figure 2, FTIR spectra exhibit characteristic bands for $\alpha$-helix, $\beta$-sheet, $\beta$-turn, and random coil conformations in the amide I (1700-1600 $\left.\mathrm{cm}^{-1}\right)$ and amide II (1560-1500 $\left.\mathrm{cm}^{-1}\right)$ regions [25].
Among these regions, amide I (due to the $\mathrm{C}=\mathrm{O}$ stretch vibrations of the peptide linkages) is more sensitive to protein secondary structures. It is well established that $\alpha$-helical conformation has an amide I and II (mainly from in-plane $\mathrm{N}-\mathrm{H}$ bending and from the $\mathrm{C}-\mathrm{N}$ stretching vibration) bands between 1657 and $1650 \mathrm{~cm}^{-1}$, and between 1550 and $1540 \mathrm{~cm}^{-1}$, respectively [26]. The $\beta$-sheet has an amide I and II bands between 1635 and $1615 \mathrm{~cm}^{-1}$, and between 1535 and $1520 \mathrm{~cm}^{-1}$, respectively [27].

Our findings indicated the presence of the amide I band by the maximum peak around $1650 \mathrm{~cm}^{-1}$ region for the three proteins, which is a characteristic feature of $\beta$-structure, and arises primarily because of the stretching vibration of the main chain of carbonyl groups in the protein backbone coupled with the in-plane N-H bending and $\mathrm{C}-\mathrm{N}$ stretching modes [28]. The presence of the amide II band was indicated by the peak around $1495 \mathrm{~cm}^{-1}, 1462 \mathrm{~cm}^{-1}$ and $1425 \mathrm{~cm}^{-1}$ for native-, $\mathrm{Ni}$ and $\mathrm{Co}-\mathrm{Az}$ respectively, which arises because of the $\mathrm{C}-\mathrm{N}$ stretching as well as the C-N-H bending motions [11].

Unlike amide I and II, the N-H stretching vibration (3310-3270 $\mathrm{cm}^{-1}$ ) of peptide bond (-CO-NH-) is insensitive to the conformation of the polypeptide backbone as it is exclusively localized on the $\mathrm{NH}$ group. But the frequency of N-H stretching depends on the strength of the hydrogen bond. In the present study, the characteristic frequency of hydrogen bonded N-H has been observed at $3457 \mathrm{~cm}^{-1}, 3456 \mathrm{~cm}^{-1}$ and $3453 \mathrm{~cm}^{-1}$ for $\mathrm{Cu}$ (II)-, $\mathrm{Ni}$ (II)- and Co (II) Az, respectively, confirming the folded conformation of $\mathrm{Az}$. It folds into three-dimensional structure known as $\beta$-barrel structure arranged in double wound Greek key topology [29].

FTIR and amide I band results revealed that nickel- and cobalt $\mathrm{Az}$ spectra closely resembles that for native Az. Baker [30] showed that the structure of apo-Az is practically identical to that of the holo-protein. The copper ligands are held in place owing to the existence of a tight cluster of hydrogen bonds as well as van der Waals interactions, and the surrounding structure is the most tightly constrained, least flexible part of the whole molecule. This has led to the idea that the protein imposes fairly rigid coordination geometry on the copper site [31] which is mainly kept even when the metal is substituted. The Az metal site is tailored for copper binding since it offers three strong equatorial ligands and two weakly bound axial ligands.

Moratal, et al. [32] showed that $\mathrm{Az}$ can bind different metals without drastic conformational changes, but the rigidity of the metal site cannot prevent slight reorganizations, including some distortions at the polypeptide backbone and side-chain atoms in the proximity of the co-ordination center. To rationalize the different binding modes of $\mathrm{Cu}-, \mathrm{Co}-$ and $\mathrm{Ni}$, their particular characteristics can be considered. In conclusion, the overall structure of $\mathrm{Az}$ is not modified by the metal exchange and the only differences with regard to the native copper $\mathrm{Az}$ occurred in the metal site region. These variations affect principally the axial ligands. Nickel co-ordinates more strongly to the carbonyl oxygen of Gly45 while its distance to the Met121 S4 enlarges up to $0.330 \mathrm{~nm}$. The resulting metal center structure can be described as distorted tetrahedral. It might not be expected that such relatively small differences would result in large differences in their interactions with proteins, but differences in electronic structure along metals play their part too, and the coordination geometries of host proteins can be exquisitely discriminating. Small differences in distances, especially if they involve charged groups, may well change the energy of interaction sufficiently to make a large difference to biological outcome. Chen, et al. [33] showed that even subtle changes in the structure of metal complexes can result in dramatic changes in their physicochemical and thus biological properties. 


\section{Differential scanning calorimetry}

It seemed of interest to find out whether the replacement of copper affects the structural stability of Az. In metallo-proteins, the understanding of the contribution of the metal ion to the thermodynamic stability of the protein structure can be investigated through studying of DSC. With this aim, denaturation experiments were carried out on native-, nickel- and cobalt-Az. Denaturation was achieved by heating and was monitored by DSC.

A common feature of all the proteins analyzed, is the irreversibility of the calorimetric transition, as indicated by the absence of endothermic effects on a second scan of the samples (data not shown). Both the Tm value and the irreversible character of the thermal transition of all proteins are in agreement with the DSC data previously reported [34,35].

All Az samples showed a single calorimetric peak (data not shown) while the comparison of the three curves evidences some differences. The main differences of the $\mathrm{Ni}$ and Co derivatives with respect to the $\mathrm{Cu}$ form are: (i) a lower thermal stability in terms of denaturation temperature as the temperature of maximum heat absorption (Tmax) is about $62^{\circ} \mathrm{C}$ and $67^{\circ} \mathrm{C}$ for $\mathrm{Ni}$ - and $\mathrm{Co}-\mathrm{Az}$ respectively, whereas for $\mathrm{Cu}$ protein the same parameter is about $74^{\circ} \mathrm{C}$. (ii) lower symmetry of the curve.

The relative instability of the nickel complex is readily understood in terms of simple ligand-field theory which shows that the loss in ligandfield stabilization energy as a result of the change from octahedral to tetrahedral symmetry is greatest in the case of $\mathrm{d}^{8}$ ions [36].

The corresponding values of the temperature of maximum heat capacity (Tmax) and the experimental enthalpy values $(\Delta \mathrm{H})$ values as a function of the scan rates are listed in Table 1.

The enthalpy data appear to give an indication of the relative stabilities of the various metallated forms. In particular, it suggests that $\mathrm{Cu}$ stabilizes the folded form of the protein more than Co and that either of these derivatives is more stable than the Ni derivative (Table1). This is in agreement with Engeseth and McMillin [34] who showed that $\mathrm{Cu}$-azurin had the highest denaturation enthalpy. Leckner, et al. [37] showed that copper ion is coordinated to the polypeptide chain in five positions and these interactions contribute to the $\mathrm{Az}$ stability.

The reduced stability of the Co- and Ni-Az is evident from both the downward shift of transition temperature from native to denaturated state of the protein as well as from the decrease of $\Delta \mathrm{H}$ value which may be explained by change in the metal center which is better described as a distorted tetrahedron, instead of trigonal bipyramidal as in the $\mathrm{Cu}$ $\mathrm{Az}$ [21]. These results suggest that the metal substitution is less effective in stabilizing Az. Bonander, et al. [38] showed that the presence of both a disulfide bridge and a copper atom enhance the structural stability of native Az.

\section{Role of metals in toxicity of azurin in vitro}

Experiments involving $P$. aeruginosa bacterium and cancer cells have demonstrated that $\mathrm{Az}$ secretion occurs mainly in presence of cancer cells in the medium, whereas in the absence of them very little

Table 1. Comparison between maximum heat capacity and experimental enthalpy values for $\mathrm{Cu}-, \mathrm{Co}-$ and Ni-azurin obtained by using DSC at scanning rate $1^{\circ} \mathrm{C} / \mathrm{min}$.

\begin{tabular}{|c|c|c|}
\hline Sample & $\begin{array}{c}\text { Maximum heat capacity } \\
(\mathbf{T m})^{\circ} \mathbf{C}\end{array}$ & $\begin{array}{c}\text { Experimental enthalpy } \\
\text { values }(\Delta \mathbf{H})(\mathbf{K J} / \mathbf{g})\end{array}$ \\
\hline $\mathrm{Cu}-\mathrm{Az}$ & 74.39 & 648 \\
\hline $\mathrm{Co}-\mathrm{Az}$ & 66.99 & 556.44 \\
\hline $\mathrm{Ni}-\mathrm{Az}$ & 62.37 & 476.66 \\
\hline
\end{tabular}

secretion of this protein was verified. These findings point out the possible existence of a sensing mechanism in bacteria that could lead to $\mathrm{Az}$ secretion in the presence of cancer cells, which they could sense as a threat or competitor to their own growth [39]. The possibility of these proteins to act on different pathways, like controlling apoptosis and cell invasion processes make them a unique weapon to be explored in the future years.

Despite a wealth of studies on Az-metal interactions, there has been less focus on the effect of this process on $\mathrm{Az}$ toxicity. It emerges that the roles of metal ions in Az toxicity can vary dramatically. As it was mentioned above, $\mathrm{Az}$ by itself enters cancer cells preferentially. Accordingly, if it is conjugated to Co- or Ni, it may be more specifically localized at the tumor site and exerts its apoptosis-inducing function, harming much less normal cells. We may take better advantage of the $\mathrm{Az}$ anti-tumor activity, making its action more selective, more efficient and enhance Az cytotoxicity with minimal side effects on normal tissues by metal replacement. Maret [40] showed that metal substitution is an important mechanism in pathophysiology and toxicology, because functions of metalloproteins depend on the type of metal ion.

The second main objective in this work was to study the effect of $\mathrm{Az}$ modification (with Co and Ni) on its anti-tumor effect (using SRB assay) on cancer cell lines from human breast and colon cells (MCF7 and HCT116, respectively). Az (from Pseudomonas aeruginosa) was used as positive control in order to compare their relative effects, since its cytotoxicity toward tumor cells was already described.

In-vitro cytotoxicity of $\mathrm{Az}$ samples was obtained using SRB treatment against MCF7and HCT116 cells treated with $\mathrm{Cu}-$, Co- and $\mathrm{Ni}-\mathrm{Az}$ at different concentrations $(0,5,12,25,50 \mu \mathrm{g} / \mathrm{ml})$ for 24 hours and the data is reported in Figures $3 \mathrm{a}, 3 \mathrm{~b}$ and $3 \mathrm{c}$ respectively.

As presented in Figure 3, the proportion of Az required for growth inhibition varies according to the cell line and the concentration of $\mathrm{Az}$ used. Figure $3 \mathrm{a}$ showed that $\mathrm{Cu}-\mathrm{Az}$ has greater significant $(\mathrm{P}<0.05)$ cytotoxic effect on HCT116- than MCF-7 cell lines at low concentrations ( 5 and $\mu \mathrm{g} / \mathrm{ml}$ ) but by increasing concentration it shows more cytotoxic effect towards MCF-7 cells ( 25 and $50 \mu \mathrm{g} / \mathrm{ml}$ ). Data revealed that $50 \mu \mathrm{g} / \mathrm{ml}$ (the highest used concentration) is the optimum concentration for $\mathrm{Cu}-\mathrm{Az}$ to be more effective as an antitumor agent for both HCT116- and MCF-7 cell lines.

Goto, et al. [41] demonstrated that the redox activity is not important for Az cytotoxicity. The fact that apo-Az (without copper) demonstrated high ROS levels and cytotoxicity, comparable to wt $\mathrm{Az}$ (with copper), appears to indicate that it is not copper but the $\mathrm{Az}$ protein that is important for its interaction with the tumor-suppressor p53 protein.

Results revealed that cobalt derivative shows a small cytotoxic effect towards both cell lines (Figure $3 \mathrm{~b}$ ). It has the best significant c'totoxic effect on HCT116- and MCF-7 cell line at concentrations of $12^{-}$and 50 $\mu \mathrm{g} / \mathrm{ml}$ respectively.

One of the most encouraging observations made in our study is that $\mathrm{Ni}$-Az with very low concentration $(5 \mu \mathrm{g} / \mathrm{ml})$ gives the same antitumor activity on HCT116 cell line as that recorded for $\mathrm{Cu}-\mathrm{Az}$ but with tenfold increase in concentration $(50 \mu \mathrm{g} / \mathrm{ml})$. While it has greater significant $(\mathrm{P}<0.05)$ cytotoxicity effect on MCF-7 cell line than that for $\mathrm{Cu}-\mathrm{Az}$ for all concentration $<50 \mu \mathrm{g} / \mathrm{ml}$ (Figure $3 \mathrm{c}$ ).

Abd-Elzaher, et al. [42] determined the anticancer properties of ferrocenyl complexes with Co (II), Ni (II), Cu (II), and Zn (II) against MCF-7. The highest antitumor activity was found for $\mathrm{Zn}$ and 


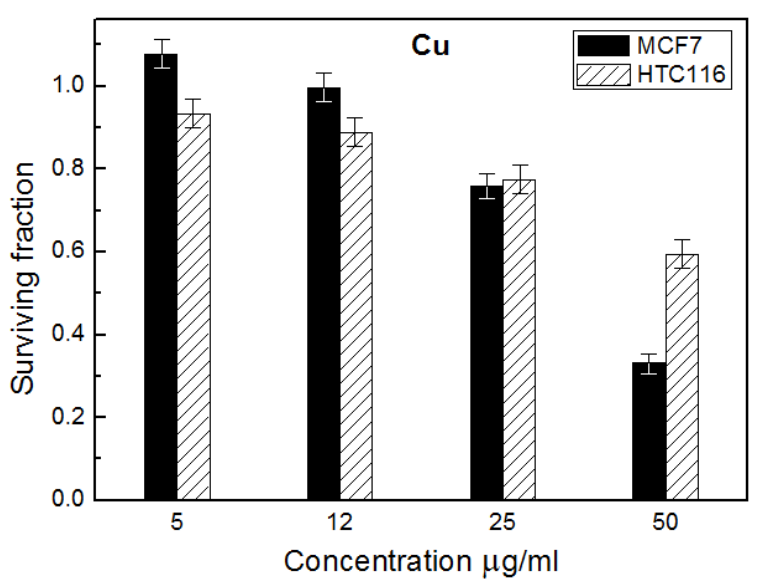

(a)

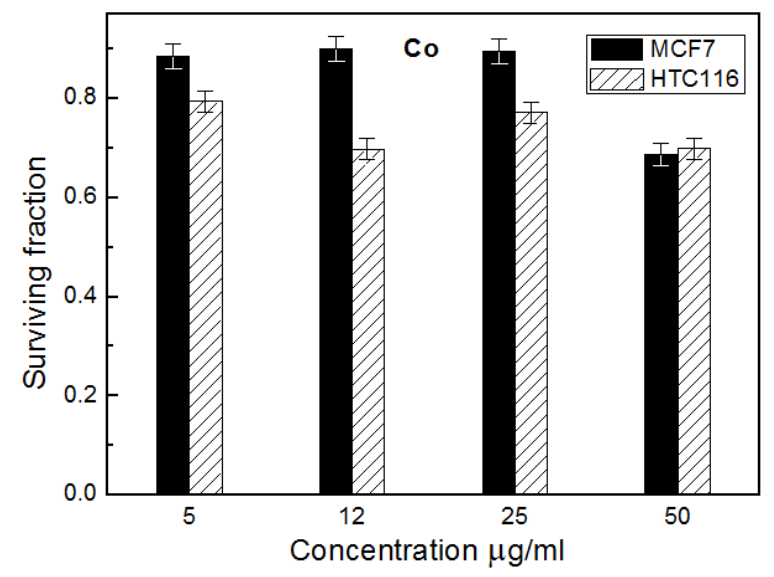

(b)

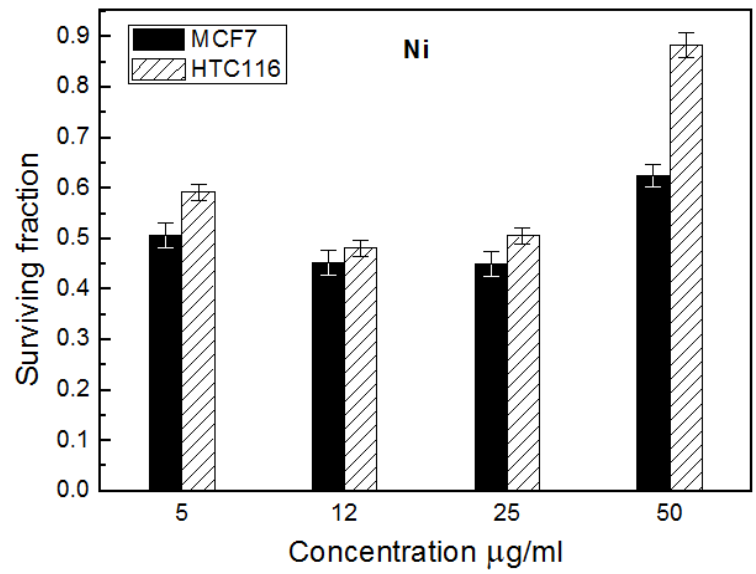

(c)

Figure 3. Cytotoxic effect of Cu-(a), Co -(b) and Ni- azurin(c) on MCF7 and HCT116 cell lines at different concentrations using SRB assay

$\mathrm{Ni}$ complexes, which resulted in the highest superoxide dismutase (SOD) activity and hydrogen peroxide $\left(\mathrm{H}_{2} \mathrm{O}_{2}\right)$ and low activities of catalase (CAT) and glutathione peroxidase (GSH-Px) as well as glutathione (GSH) level. They concluded that the antitumor effect of these complexes is exerted by production of $\mathrm{H}_{2} \mathrm{O}_{2}$. Similarly, GomesJunior, et al. [43] showed that nickel elicits a fast antioxidant response in Coffea arabica cells; $\mathrm{NiCl}_{2}$ induced the antioxidant defences by the rapid increase of the activity of all of the major antioxidant enzymes such as SOD and CAT. This is in agreement with Bienvenu, et al. [44] who showed that most chemotherapeutic agents cause cells to over generate ROS and thus are capable of inducing apoptosis and necrosis by causing oxidative damage to DNA, proteins and lipids.

On the other hand, many articles have reported DNA binding and anticancer potentials of nickel complexes owing to good affinity of $\mathrm{Ni}(\mathrm{II})$ for DNA and some DNA binding proteins $[45,46]$.

Afrasiabi, et al. [47] showed that complexation with nickel ion in semicarbazone derivative increases the inhibitory action on MCF-7 cell proliferation. Similar effect was observed upon complexation of other thiosemicarbazones with nickel (II) ion [48]. The enhancement of antiproliferation activity by metal complexes is related to an increase in the lipophilicity so they can penetrate into the cells more easily [49].

Taken together, it appears that this combination of all the above mentioned factors act in an additive or synergistic mode.
To our best knowledge, this is the first time metal replacement of $\mathrm{Az}$ has been used (with cell line) in an attempt to find derivatives with greater potency and high toxicity than the exiting Az. Data revealed that this process is the predominant reason for the effectiveness of $\mathrm{Az}$ and enhancement of its activity towards tumor cells. This is in a full agreement with Samie, et al. [50] who showed that nickel complex is a potent anti-cancer agent by simultaneous induction of intrinsic and extrinsic pathways of apoptosis as well as cell cycle arrest in colon and breast cancer cell lines.

The data presented in Figures $3 a, 3 b$ and $3 c$ are represented in Figure $4 \mathrm{a}$ and Figure $4 \mathrm{~b}$ to clarify the effect of metal substitution on anti-tumor activity of $\mathrm{Az}$ on cancer and colon cells respectively.

Figures $4 \mathrm{a}$ and $4 \mathrm{~b}$ showed that $\mathrm{Ni}-\mathrm{Az}$ can be considered as the most promising potent antitumor protein relative to the others. This is in agreement with Aliasa, et al. [51] who showed the nickel (II) complex has higher cytotoxicity than Co (II) due to high polarity and large size of this metal in complex ion. Since the high polarity gives covalent character in ionic bond to the complexes and made easy to enter in the cell. Obviously, small concentration of the used heavy metal will be more safe for healthy cells. This gives $\mathrm{Ni}-\mathrm{Az}$ greater advantage relative to the other forms. Results also revealed that $\mathrm{Ni}$ have low cytotoxic effect in high concentrations than other concentrations i.e. low and middle concentrations, this is common in toxicology and called Hormesis which means that the compound showed inhibition effect at low concentrations but not at high concentrations [51]. 


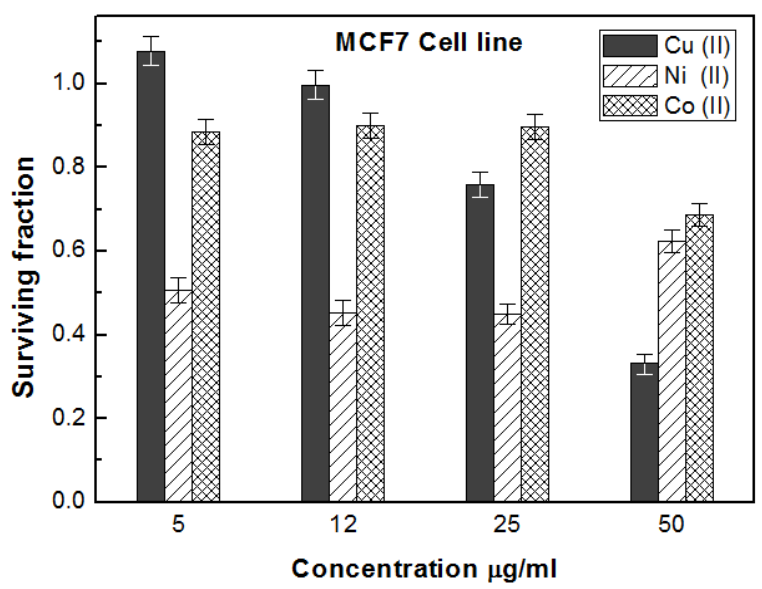

(a)

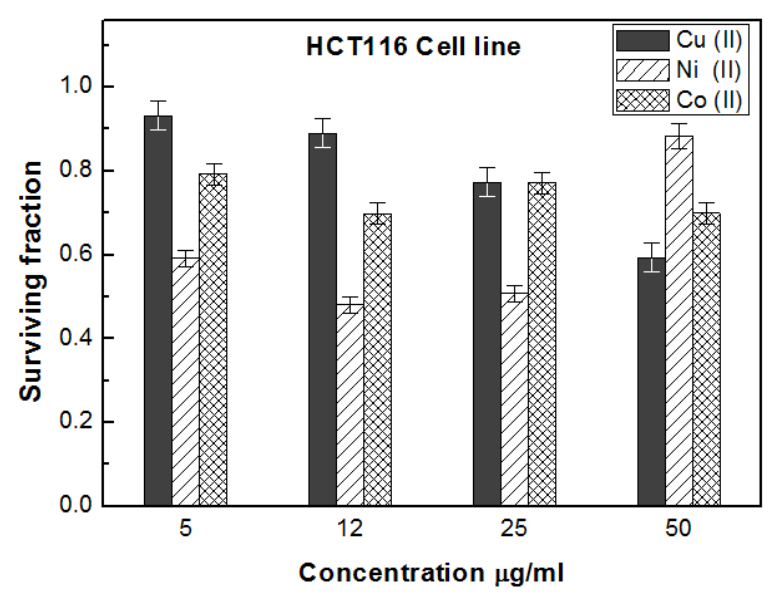

(b)

Figure 4. Cytotoxic effect of Cu-, Co-and Ni- azurin on MCF7 cell line (a) and HCT116 cell line (b) at different concentrations using SRB assay

According to these results, $\mathrm{Cu}$ and Co derivatives may be defective in complex formation with p53, generates low levels of ROS (reactive oxygen species) and lacks appreciable cytotoxicity towards breast and colon cell lines in comparison with $\mathrm{Ni}$. Many factors may be responsible in the activity of these complexes in pharmacological field like size of metal, charge distribution, geometry shape, ionic character, and polarity [52].

Obviously this observation merits further studies to truly understand the nature and significance of this replacement, but we suggest that it highlights that $\mathrm{Ni}$ may be bona fide copper ion impersonator in vivo. The next step in this field (in progress) is to relate the in vitro observations to in vivo conditions. The situation inside of cells is more complex than a dilute buffer system and one should use caution before extrapolating in vitro conclusions to the in vivo scenario.

\section{Conclusion}

We have verified that cobalt and nickel can metallate apo-Az using multiple biophysical techniques. Our idea of metal replacement was not only for enhancing $\mathrm{Az}$ antitumor activity, but to reveal the differences of Az's stability and the secondary structure. One of the encouraging observations made in our study is that $\mathrm{Ni}-\mathrm{Az}$ form has the most extensive anti-antitumor effect on breast- and colon cancer cell line.

\section{Conflict of interest}

The authors report no conflict of interest.

\section{References}

1. Ferlay J, Shin HR, Bray F, Forman D, Mathers C, et al. (2010) Estimates of worldwide burden of cancer in 2008: GLOBOCAN 2008. Int J Cancer 127: 2893-2917. [Crossref]

2. Dao K, Hanson R (2012) Targeting the estrogen receptor using steroid-therapeutic drug conjugates (hybrids). Bioconj Chem 23: 2139-2158.

3. Douglass S, Ali S, Meeson A, Browell D, Kirby J (2012) The role of FOXP3 in the development and metastatic spread of breast cancer. Cancer Metast Rev 31: 843-854.

4. Verhoeven W, Takeda Y (1956) Participation of cytochrome $\mathrm{c}$ in nitrate reduction. In: McElroy WD, Glass B (Eds) Inorganic nitrogen metabolism, Johns Hopkins Press, Baltimore, pp: 159

5. Carla H, Canters G (1992) The importance of Asn47 for structure and reactivity of azurin from Alcaligenes denitrificans as studied by site-directed mutagenesis and spectroscopy. J Biol Chem 267: 13836- 13842.

6. Jain R, Forbes N (2001) Can engineered bacteria help control cancer? Proc Nat Acad Sci USA 98: 14748-14750.
7. Zaborina O, Dhiman N, Chen ML, Kostal J, Holder IA, et al. (2000) Secreted products of a nonmucoid Pseudomonas aeruginosa strain induce two modes of macrophage killing: external-ATP- dependent, P2Z-receptor-mediated necrosis apoptosis. Microbiol 146: 2521-2530.

8. Yamada T, Goto M, Punj V, Zaborina O (2002) Bacterial redox protein azurin, tumo suppressor protein p53, and regression of cancer. Proc Nat Aca Sc USA 99: 14098-14103.

9. Yang DS, Miao XD, Ye ZM, Feng J, Xu RZ, et al. (2005) Bacterial redox protein azurin induce apoptosis in human osteosarcoma U2OS cells. Pharmacol Res 52: 413 421. [Crossref]

10. Punj V, Bhattacharyya S, Saint-Dic D, Vasu C, Cunningham EA, et al. (2004) Bacterial cupredoxin azurin as an inducer of apoptosis and regression in human breast cancer. Oncogene 23: 2367-2378. [Crossref]

11. Ramachandran S, Sarkar S, Mazumadar A, Mandal M (2011) Azurin synthesis from Pseudomonas Aeruginosa MTCC 2453, properties, induction of reactive oxygen species, and p53 stimulated apoptosis in breast carcinoma cells. J Cancer Sci Ther 3: 104-111.

12. Jungwirth U, Kowol CR, Keppler BK, Hartinger CG, Berger W, et al. (2011) Anticancer activity of metal complexes: involvement of redox processes. Antioxid Redox Signal 15: $1085-1127$

13. Choi D, Fung A, Moon H, Ho D, Chen Y, et al. (2007) Transport of living cells with magnetically assembled nanowires. Biomed Microdevices 9: 143-148.

14. Lu H, Shi X, Costa M, Huang C (2005) Carcinogenic effect of nickel compounds. Mol Cell Biochem 279: 45-67. [Crossref]

15. Van de Kamp M, Hali F, Rosato N, Finazzi-Agro A, Canters G (1990) Purification and characterization of a non-reconstitutable azurin, obtained by heterologous expression of the Pseudomonas aeruginosa azu gene in Escherichia coli. Biochim Biophys Acta 1019: $283-292$.

16. Parr SR, Barberd D, Greenwood C (1976) Purification procedure for the soluble cytochrome oxidase and some other respiratory proteins from Pseudomonas aeruginosa. Biochem J 157: 423-430.

17. Skehan P, Storeng R, Scudiero D, Monks A, McMahon J, et al. (1990) New colorimetric cytotoxicity assay for anticancer-drug screening. J Natl Cancer Inst 82: 1107-1112. [Crossref]

18. Tennent DL, McMillin DR (1979) A detailed analysis of the charge-transfer bands of a blue copper protein. Studies of the nickel (II), manganese (II) and cobalt (II) derivatives of azurin. J Am Chem SOC 101: 2307-2311.

19. Gilardi G, Mei G, Rosato N, Canters GW, Finazzi-Agro A (1994) Unique environment of Trp48 in Pseudomonas aeruginosa azurin as probed by site-directed mutagenesis and dynamic fluorescence spectroscopy. Biochem 33: 1425-1432.

20. Fuentes L, Oyola J, Fernández M, Quinones E (2004) Conformational changes in azurin from Pseudomona aeruginosa induced through chemical and physical protocols. Biophys J 87: 1873-1880.

21. Czernuszewicz R, Frackiewicz G, Zareba A (2005) A detailed resonance Raman spectrum of nickel (II)-substituted Pseudomonas aeruginosa Azurin. Inorg Chem 44: $5745-5752$ 
22. McMillin DR, Rosenberg RC, Gray HB (1974) Preparation and spectroscopic studies of cobalt(II) derivatives of blue copper proteins. Proc Natl Acad Sci U S A 71: 47604762. [Crossref]

23. Malmstr?m BG (1994) Rack-induced bonding in blue-copper proteins. Eur J Biochem 223: $207-216$

24. Nar H, Huber R, Messerschmidt A, Filippou AC, Barth M, et al. (1992) Characterization and crystal structure of zinc azurin, a by-product of heterologous expression in Escherichia coli of Pseudomonas aeruginosa copper azurin. Eur J Biochem 205: 1123-1129.

25. Kong J, Yu S (2007) Fourier transform infrared spectroscopic analysis of protein secondary structures. Acta Biochimica Biophysica Sinica 39: 549-559.

26. Lyman D, Murray-Wijelath J, Feughelman M (2001) Effect of temperature on the conformation of extended a-Keratin. Appl Spectrosc 55: 552-554.

27. Goormaghtigh E, Ruysshaert J, Raussens V (2006) Evaluation of the information content in infrared spectra for protein secondary structure determination. Biophys $J$ 90: 2946-2957.

28. Surewicz WK, Szabo AG, Mantsch HH (1987) Conformational properties of azurin in solution as determined from resolution-enhanced Fourier-transform infrared spectra. Eur J Biochem 167: 519-523.

29. Adman E (1991) Copper protein structures. Adv Protein Chem 42: 145-197. [Crossref]

30. Baker EN (1991) The relative rigidity of the type I copper site in azurin as seen in high resolution X-ray analysis of various forms of the protein. J Inorg Biochem 43: 162.

31. Gray H, Malmstrom B (1983) On the relationship between protein-forced ligand fields and the properties of blue copper centers. Comments Inorg Chem 2: 203-210.

32. Moratal JM, Romero A, Salgado J, Perales-Alarcón A, Jiménez HR (1995) The crystal structure of nickel(II)-azurin. Eur J Biochem 228: 653-657. [Crossref]

33. Chen D, Milacic V, Frezza M, Dou QP (2009) Metal complexes, their cellular targets and potential for cancer therapy. Current Pharmaceutical Design 15: 777-791.

34. Engeseth HR, McMillin DR (1986) Studies of thermally induced denaturation of azurin and azurin derivatives by differential scanning calorimetry: evidence for copper selectivity. Biochem 25: 2448-2455.

35. Sandberg A, Leckner J, Shi Y, Schwaz FP, Karlsson BG (2002) Effects of metal ligation and oxygen on the reversibility of the thermal denaturation of Pseudomonas aeruginosa azurin. Biochem 41: 1060-1069.

36. Douglas B, McDaniel DH, Alexander JJ (1983) Concepts and models of inorganic chemistry, 2 nd edition, John Wiley and Sons, Inc, NY.

37. Leckner J, Bonander N, Wittung-Stafshede P, Malmstrom BG, Karlsson BG (1997) The effect of the metal ion on the folding energetics of azurin: a comparison of the native, zinc and apoprotein. Biochem Biophys Acta 1342: 19-27.

38. Bonander N, Leckner J, Guo H, Karlsson BG, Sjolin L (2000) Crystal structure of the disulfide bond-deficient azurin mutant $\mathrm{C} 3 \mathrm{~A} / \mathrm{C} 26 \mathrm{~A}$. How important is the S-S bond for folding and stability? Eur J Biochem 267: 4511-4519.
39. Fialho A, Chakrabarty A (2007) Recent patents on bacterial proteins as potential anticancer agents. Recent patents on anti-cancer drug discovery 21: 224-234.

40. Maret W (2010) Metalloproteomics, metalloproteomes, and the annotation of metalloproteins. Metallomics 2: 117-125.

41. Goto M, Yamada T, Kimbara K, Horner J, Newcomb M, et al. (2003) Induction of apoptosis in macrophages by Pseudomonas aeruginosa azurin: tumour-suppressor protein p53 and reactive oxygen species, but not redox activity, as critical elements in cytotoxicity. Molec Microbiol 47: 549-559.

42. Abd-Elzaher MM, Moustafa SA, Labib AA, Ali MM (2010) Synthesis, characterization, and anticancer properties of ferrocenyl complexes containing a salicylaldehyde moiety. Monatsh Chem 141: 387-393.

43. Gomes-Juniora RA, Moldesa CA, Delitea FS, Gratãoa PL, Mazzaferab P, et al. (2006) Nickel elicits a fast antioxidant response in Coffea arabica cells. Plant Physiology and Biochemistry 44: 420-429.

44. Bienvenu P, Caron L, Gasparutto D, Kergonou JF (1992) Assessing and counteracting the prooxidant effects of anticancer drugs in free radicals and aging. EXS, , Ingrid Emerit, Britton Chance (eds), Berlin 62: 257-265.

45. Shobana S, Dharmaraja J, Selvaraj S (2013) Mixed ligand complexation of some transition metal ions in solution and solid state: Spectral characterization, antimicrobial, antioxidant, DNA cleavage activities and molecular modelling. Spectrochimica Acto Part A: Molecular and Biomolecular Spectroscopy 107: 117-132.

46. Hsu CW, Kuo CF, Chuang SM, Hou MH (2013) Elucidation of the DNA-interacting properties and anticancer activity of a Ni(II)-coordinated mithramycin dimer complex. Biometals 26: 1-12.

47. Afrasiabi Z, Sinn E, Lin W, Ma Y, Campana C, et al. (2005) Nickel (II) complexes of naphthaquinone thiosemicarbazone and semicarbazone: Synthesis, structure, spectroscopy, and biological activity. Journal of Inorganic Biochemistry 99: 15261531.

48. Ferrari MB, Capacchi S, Reffo G, Pelosi G, Tarasconi P, et al. (2000) Synthesis, structural characterization and biological activity of p-fluorobenzaldehyde thiosemicarbazones and of a nickel complex. Journal of Inorganic Biochemistry 8: 89-97.

49. Petering HG, Van Giessen GJ (1966) Biochem Copper. Proc Symp Harriman, NY, pp: 197-208.

50. Samie N, Haerian BS, Muniandy S, Kanthimathi MS (2016) Novel nickel complex compound reactivates the apoptotic network, cell cycle arrest and cytoskeletal rearrangement in human colon and breast cancer cells. International Journal of Pharmacological and Pharmaceutical Sciences 3: in press.

51. Aliasa M, Seewana AN, Shakirb C, Mohamma FI (2014) Cytotoxicity assay of nickel and cobalt (II) complexes of 5-(4-nitro phenyl)-4-amino-3-mercapto propenyl-1, 2, 4-triazole on HepG2 cell line. Int J Pharm 4: 126-132.

52. Sadler PJ (1982) Inorganic pharmacology. Chem Brit 18: 182-188.

Copyright: @2017 Ali MA. This is an open-access article distributed under the terms of the Creative Commons Attribution License, which permits unrestricted use, distribution, and reproduction in any medium, provided the original author and source are credited. 